\title{
EUNETHTA: FURTHER STEPS TOWARDS EUROPEAN COOPERATION ON HEALTH TECHNOLOGY ASSESSMENT
}

Eleanor Woodford Guegan

National Institute for Health Research (NIHR) Evaluation Studies and Trials Co-ordinating Centre, University of Southampton, Southampton, UK

\author{
Mirjana Huić \\ Agency for Quality and Accreditation in Health Care and Social Welfare, Zagreb, Croatia \\ Conor Teljeur \\ Health Information and Quality Authority, Dublin, Ireland
}

Key words: Program Evaluation, International Cooperation, Comparative Effectiveness Research, Health Technology Assessment

The European network for Health Technology Assessment (EUnetHTA) was established to increase cooperation in European health technology assessment (HTA) by developing a common set of tools, methods, documents, and HTA information. The collaboration is well recognized within the European HTA community and at an international level. Timely and efficient usage of European HTA resources is possible as demonstrated by EUnetHTA partners and associates successfully working together.

Factors that support collaboration include knowledge of each other's work plans, use of common templates and methodology, and using a common scientific and working "language." HTA is a resource intensive activity with a heavy burden of evidence gathering. The sharing of data and findings in a standardized manner has the potential to reduce those resource requirements. Although tools were developed within the EUnetHTA Joint Action, their use is not restricted to the European setting. This Special Issue describes the EUnetHTA Joint Action (JA) project (2010-2012) as a further step towards sustainable European cooperation on HTA which can add value at the European, national and regional levels.

Several networks have aimed to increase international collaboration in HTA, including the International Network of Agencies for Health Technology Assessment (INAHTA), Health Technology Assessment international (HTAi) and HTAsiaLink. Since the mid-1990s, the European Union (EU) Commission has supported several initiatives to increase cooperation and share information between HTA agencies within the European community. The European network of HTA (EUnetHTA) stemmed from previous work in this area: EUR-ASSESS (1994-97), HTA Europe (1997-98), and ECHTA/ECAHI (2000-02).

The first 3-year EUnetHTA project (2006-08) sought to "provide reliable, timely, transparent, and transferable information on the short- and long-term effects of health technologies as input to decision making in Member States of the EU" through the development of a set of practical tools for HTA (1). The outputs included the HTA Core Model (a framework for structuring an HTA report into standardized assessment elements), information for decision makers about emerging technologies, and collaboration on access with evidence generation. Recommendations were made at the end of the project, including the need to continue developing and evaluating these HTA tools in real-life settings (1).

Three additional years of EU funding was granted for a EUnetHTA joint action (2010-12). This JA1 project recruited thirty-eight government-appointed organizations from twentysix EU member states, Norway, and Croatia. The work was structured into eight work streams. The Executive Committee provided strategic leadership of the project, all member agencies met yearly in the Plenary Assembly, and a Stakeholder Forum facilitated information exchange.

The project's overarching aim was to "establish an effective and sustainable HTA collaboration in Europe that brought added value at the regional, national and European level", with three specific objectives:

- Development of HTA tools and methods; developing principles, methodological guidance, and functional online tools and policies;

- Application and field-testing of developed tools and methods; and

- Development of a general strategy and business model for sustainable European collaboration on HTA.

\section{DEVELOPING PRINCIPLES, TOOLS, AND GUIDANCE}

This IJTAHC special issue describes the set of tools developed within EUnetHTA to facilitate collaboration on HTA projects. The HTA Core Model was expanded into an online version for easy access and use; it is anticipated that the online version will contribute directly to reducing duplication of effort by HTA agencies (Lampe et al.). A reduced version of the Core Model facilitating rapid assessment of the relative effectiveness of pharmaceuticals, taking place shortly after market authorization and within strict timelines, required a different 
approach from routine technology assessments (Kleijnen et al.). The Planned and Ongoing Projects (POP) Database facilitates and encourages cross-agency collaboration by identifying identical or similar projects across agencies. The POP Database was extended and evaluated during JA1 (Wild et al.). Although the Database contributed to collaboration and to planning projects so as to benefit from published outputs of other agencies, the impact has been limited and further work is required to determine how to stimulate collaboration (Vondeling and Sandvei).

A series of methodological guidelines were also developed for assessing the relative effectiveness of pharmaceuticals. The guidelines covered topics such as endpoints, comparators, direct and indirect comparisons, validity, and applicability. The selection of inadequate endpoints leads to poor decision making, but this risk can be moderated by using clear guidance on how to choose appropriate endpoints (Pavlovic et al.).

The EUnetHTA information management system was enhanced by testing various solutions to improve collaboration, disseminate information, and enhance interoperability of these tools (Chalon and Krämer). The tools and guidelines were designed and implemented to foster a unified approach to HTA, which increases transferability of findings and reduces duplication.

Tool and guideline development also brought challenges. Some of these were technical and were solved using information technology resources. Other issues related to legitimate differences in HTA methodology across member agencies. Guidelines, for example, had to strike a balance between being sufficiently broad to achieve consensus on content and also being specific enough to give concrete guidance.

\section{APPLICATION OF TOOLS AND METHODS}

A pilot rapid assessment of a pharmaceutical involved a large number of agencies and individuals, and provided valuable lessons in logistics and the trade-off between resources and duplicated work (Kleijnen et al.). Testing of developed tools brought valuable lessons. The HTA Core Model, for example, does not map directly onto a national HTA report but shows substantial overlap, indicating that adoption of the Core Model for reporting may not compromise the outputs of many agencies (Pasternack et al.). Adopting the Core Model could increase the transferability of HTAs across countries. Cross-country collaboration can decrease workload despite the challenges in creating the infrastructure to support it, for example, the use of different languages (Lo Scalzo et al.).

\section{DEVELOPING A SUSTAINABLE MODEL OF COLLABORATION}

Any large scale international collaboration brings major logistical difficulties, so significant resources were devoted to EUnetHTA coordination, dissemination, evaluation, and strategic development. The value of HTA practitioners across a continent getting to know each other and how to work together should not be under-estimated. In addition to ensuring active engagement by partner agencies, a wide variety of external agencies and stakeholders were involved. Key factors for the project's success included achievement of objectives according to the work plan, good communication, and clear work stream management. Progress achieved in the preceding EUnetHTA project provided a good foundation. On the other hand, application and field testing of the tools has not been fully explored in the "real world" situation (Woodford Guegan and Cook). Therefore, a follow-up project, EUnetHTA JA2, continues work started in JA1 (2).

The papers in this special EUnetHTA edition of the IJTAHC follow the order of describing Tools \& Methodology, Pilots \& process, and Success factors for international HTA projects.

\section{TOWARDS THE FUTURE}

EUnetHTA JA2 will strengthen the practical application of tools for cross-border HTA collaboration and achieve a better understanding of ways to establish a sustainable structure for the HTA work in the EU. It aims at producing recommendations for the design and management of future HTA cooperation in Europe, according to Article 15 of the EU Directive for cross-border healthcare (3). Other developments in the legal framework and strategy of the European cooperation on HTA include: Commission Implementing Decision on HTA Network and its Rules of Procedures, Multiannual work program 2014-15 and the Strategy Paper on the long-term provisions. EUnetHTA performs an essential function in the scientific and technical cooperation mechanism (4-6). The strategic level (HTA Network) and the scientific and technical level (EUnetHTA) should be synergistic and complementary and should work in close cooperation.

In EUnetHTA JA2, core HTA information-both full and rapid assessments - is produced in collaboration with methods developed in EUnetHTA JA1. The information and knowledge management tools will be refined and finalized, additional methodologies, guidelines, and common submission templates will be developed, and training for partners and stakeholders provided.

Partners in EUnetHTA aim at continuing the collaboration and strengthening the foundation for sustainable European cooperation on HTA. The ultimate goal is to make a positive difference to patients and improve the quality of health care, through reducing duplications, improving quality, facilitating timely production of national HTA reports and supporting sound decision-making processes.

\section{CONTACT INFORMATION}

Eleanor Woodford Guegan, PhD, Senior Research Fellow, National Institute for Health Research (NIHR) Evaluation Studies and Trials Co-ordinating Centre, University of Southampton, Southampton, UK 
Mirjana Huić, MD, PhD (mirjana.huic@aaz.hr), Assistant Director, Department for Development, Research and Health Technology Assessment, Agency for Quality and Accreditation in Health Care and Social Welfare, Zagreb, Croatia

Conor Teljeur, PhD, Senior Statistician, Health Technology Assessment, Health Information and Quality Authority, Dublin, Ireland

\section{CONFLICTS OF INTEREST}

Eleanor Woodford Guegan reports grants from NIHR HTA Programme and European Commission - DG Sanco, and membership of the EUnetHTA executive committee. The views and opinions expressed herein are those of the authors and do not necessarily reflect those of the Health Technology Assessment (HTA) Programme, NIHR, NHS or the Department of Health. The other authors report they have no potential conflicts of interest.

\section{REFERENCES}

1. Kristensen FB, Lampe K, Chase DL, et al. Practical tools and methods for health technology assessment in Europe: Structures, methodologies, and tools developed by the European network for Health Technology Assessment, EUnetHTA. Int J Technol Assess Health Care. 2009;25(Suppl 2):1-8.

2. European network for HTA Joint Action 2. www.eunethta.eu/sites/ 5026.fedimbo.belgium.be/files/Technical\%20Annex1b\%20of $\% 20$ the $\%$ 20EUnetHTA\%20JA\%202\%20Grant\%20Agreement.pdf (accessed November 5, 2014).

3. Directive 2011/24/EU of the European Parliament and of the Council of 9 March 2011 on the application of patients' rights in cross-border healthcare. http://eur-lex.europa.eu/legal-content/ EN/TXT/HTML/?uri=URISERV:sp0002\&rid=1 (accessed November 5, 2014).

4. Commission Implementing Decision of 26 June 2013 providing the rules for the establishment, management and transparent functioning of the Network of national authorities or bodies responsible for health technology assessment. Official Journal of the European Union L 175/71. http://ec.europa.eu/health/technology_assessment/docs/impl_dec_hta_ network_en.pdf (accessed November 5, 2014).

5. Rules of Procedure of the Health Technology Assessment Network. Adopted at the 1st HTA network meeting, 16 October 2013. http://ec.europa.eu/health/technology_assessment/docs/hta_network_ rules_procedures_en.pdf (accessed November 5, 2014).

6. Multiannual work programme 2014-2015. Adopted at the 1st HTA network meeting, 16 October 2013. http://ec.europa.eu/health/ technology_assessment/docs/hta_network_wp2014_15_en.pdf (accessed November 5, 2014). 